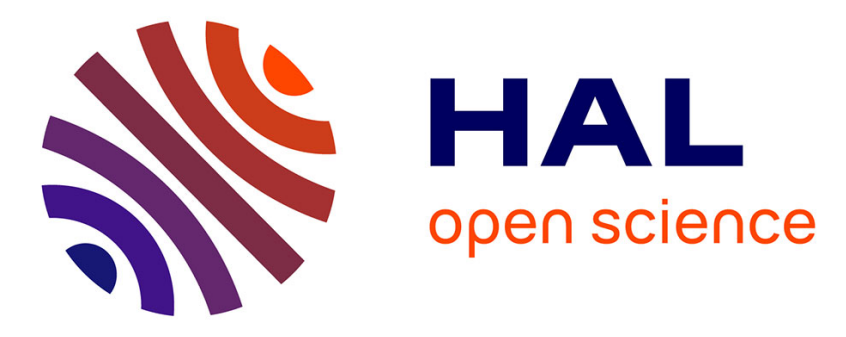

\title{
Evolution of the Mechanical Properties During the Gel-Glass Process
}

Thierry Woignier, Florence Despetis, P. Etienne, Adil Alaoui, L Duffours, Jean Phalippou

\section{- To cite this version:}

Thierry Woignier, Florence Despetis, P. Etienne, Adil Alaoui, L Duffours, et al.. Evolution of the Mechanical Properties During the Gel-Glass Process. Lisa Klein; Mario Aparicio; Andrei Jitianu. Handbook of Sol-Gel Science and TechnologyProcessing: Characterization and Applications, , pp.1487 - 1512, 2018, 978-3-319-32099-1. 10.1007/978-3-319-32101-1_43 . hal-01929802

\section{HAL Id: hal-01929802 https://hal-amu.archives-ouvertes.fr/hal-01929802}

Submitted on 21 Nov 2018

HAL is a multi-disciplinary open access archive for the deposit and dissemination of scientific research documents, whether they are published or not. The documents may come from teaching and research institutions in France or abroad, or from public or private research centers.
L'archive ouverte pluridisciplinaire HAL, est destinée au dépôt et à la diffusion de documents scientifiques de niveau recherche, publiés ou non, émanant des établissements d'enseignement et de recherche français ou étrangers, des laboratoires publics ou privés. 


\title{
Evolution of the Mechanical Properties During the Gel-Glass Process
}

\author{
Thierry Woignier, Florence Despetis, P. Etienne, Adil Alaoui, \\ L. Duffours, and Jean Phalippou
}

\author{
T. Woignier $(\bowtie)$ \\ IMBE, CNRS, IRD, Aix Marseille Université, Avignon Université, Marseille, France \\ IRD - Campus Agro Environnemental Caraïbes, Le Lamentin, Martinique, France \\ e-mail: thierry.woignier@imbe.fr \\ F. Despetis · J. Phalippou \\ Laboratoire Charles Coulomb, Université Montpellier 2, Montpellier Cedex 5, France \\ P. Etienne \\ Laboratoire Charles Coulomb, Montpellier Université, Le Lamentin, Montpellier, France
A. Alaoui
Faculté des Sciences et Techniques de Tanger, Tanger, Morocco
L. Duffours
PRIME Verre, Montpellier, France Le Lamentin, Martinique, France 


\section{Abstract}

Different kinds of structure in alcogels and aerogels (fractal or not fractal) can be synthesized by a control of the chemical parameters and also by different steps in the preparation such as sintering and plastic compaction. The porosity of the gels is affected either by the adjustment of the gelifying concentration, by a precise control of the viscous flow sintering process, or by an isostatic pressure deformation. The different kinds of gels cover the whole range of porosity between $99 \%$ and $0 \%$, and their mechanical properties (elastic modulus, strength, toughness) are strongly dependent on the porosity but also on their structure. We follow the mechanical properties of the over the whole process alcogel - aerogel - glass. They vary by five orders of magnitude as a function of the density, and for the same relative density, the elastic modulus and strength can increase by one order of magnitude due to a change in connectivity. The influence of the sintering process compared to isostatic pressure on the mechanical properties is explained by the associated structural changes.

\section{Introduction}

The most fascinating features of gels (low sound velocity, high specific surface area, low thermal and electric conductivity, etc.) are generally due to their very large porosity, which can be as high as $99 \%$. However, the counterpart of this huge porosity is poor mechanical properties and the consequence is that gels tend to crack during drying. So, one of the most difficult problems in sol-gel science is to make large bodies of dried gels (xerogels or aerogels).

The drying stresses are attributed to capillary phenomena and differential strain which result from a pressure gradient in the pore liquid (Brinker and Scherer 1990). Different ways have been studied to solve this problem, for example, supercritical drying (SD) allows one to avoid the capillary stresses and monolithic aerogel can be obtained (Kistler 1932).

The potentialities of this material (Cerenkov detector, acoustic or thermal insulator, host matrix for catalysts) are increased if considered not only as an end product but as a precursor. By a set of sintering treatments, the silica aerogels can be easily transformed into pure silica glass (Woignier et al. 1990), and appropriate heat treatments lead to Partially Dense Aerogel (PDA) which can be used as a host matrix for the synthesis of doped glasses or composites (Reynes et al. 2001; Woignier et al. 2011).

The mechanical behavior of gels, xerogels and aerogels, is generally described in terms of brittle and elastic materials, like glass or ceramics (West et al. 1988; Zarzycki 1988; Woignier and Phalippou 1988a; Hafidi-Alaoui et al. 2000; Despetis et al. 2004; Woignier et al. 2015). During mechanical testing even for very porous material (99\%), the stress-strain curve shows a perfect elastic behavior and the conchoidal fracture morphology indicates that the material is brittle, like a conventional glass. The main difference, compared to silica glass, is the order of magnitude 
of the elastic and mechanical moduli which are $10^{4}$ times lower. However, if this analogy is pertinent when gels are under a tension stress (bending test), they exhibit a more complicated response when the structure is compressed (compression test). The network is linearly elastic under small strains, then exhibits yield, followed by densification and plastic hardening (Pirard et al. 1995; Scherer et al. 1995; Duffours et al. 1995; Perrin et al. 2004; Phalippou et al. 2004). As a consequence of the plastic shrinkage, it is possible to eliminate the pores and stiffen the gel at room temperature. We will see that these opposite behaviors (elastic and plastic) are surprisingly related to the same two kinds of gel features: the silanol content and the pore size distribution. Different kinds of gel structure (fractal or not fractal) have been synthesized, through a control of the different steps of transformation, such as sintering and plastic compaction and were studied as a function of their structure. The influence of the sintering process, compared to the plastic transformation, on the elastic properties and mechanical behavior is explained by the associated structural changes. The relationships between structural and mechanical properties will be discussed in terms of the cellular model, percolation theory, fractal structure, and the blobs and links model.

\section{Experimental Procedure}

Different families of gels have been elaborated for these studies. The main are silica alcogels and aerogels. The alcogels are prepared by hydrolysis and polycondensation reactions of tetramethoxysilane (TMOS). The TMOS is dissolved in various amounts of ethanol, thereby adjusting the oxide content of the sol (and the final bulk density of the material). The solutions are hydrolyzed under neutral, basic $\left(\mathrm{NH}_{4} \mathrm{OH}\right.$, $\left.5 \times 10^{-2} \mathrm{~N}\right)$, or acidic $\left(\mathrm{HNO}_{3}, 10^{-4} \mathrm{~N}\right)$ conditions. The alcogels are transformed into aerogels by supercritical evacuation of the solvent. For several samples, the supercritical heat treatment is not followed by the evacuation of the superfluid, so the solvent invades the gel during cooling. The interest of this procedure is to prepare materials full of solvent for which the solid network has undergone the same heat treatment as for classical aerogels. These samples are called "rewetted aerogels." The samples are labeled N, B, or A (with respect to the catalyst), followed by the TMOS weight percent.

The densification of the aerogels is obtained by heat treatment at a temperature of $1050{ }^{\circ} \mathrm{C}$ and, as a function of the sintering time, the bulk density increases. The samples are labeled PDAxx (Partially Dense Aerogel) where xx is the bulk density expressed in $\mathrm{g} / \mathrm{cm}^{3}$. The PCAxx samples (Partially Compressed Aerogel) correspond to gels whose density has been increased by room temperature compression.

The elastic moduli and the modulus of rupture of the samples were measured by the three-point bending technique, using an Instron testing machine with a $20 \mathrm{~N}$ load cell and by sound velocity. The fracture toughness was measured using the singleedge notched beam (SENB) method in the three-point bending. Generally, the beam bending data allow calculation of Young's modulus, $E$. That is true for aerogels, but, in the case of the alcogel samples, the beam bending test yields the shear modulus, $G$. 
Due to the low permeability of the alcogels, the fluid forces the network to behave as if it were incompressible. Then the volume of the sample is unchanged by the deformation, and the fluid exerts a transverse stress on the gel network, providing a measurement of the shear modulus $G$ (Scherer et al. 1988). In order to compare the elastic properties of the aerogels and the alcogels, the measurements have been made on alcogels and rewetted aerogels.

Their structure will be characterized by small-angle scattering techniques (SANS and SAXS). Scattering vectors $q$, ranging from 0.0018 to $0.3 \AA^{-1}$, were explored to allow a determination of the density-density correlation function in the length scale from 3 to $500 \AA$.

\section{Mechanical Behavior of Alcogels and Aerogels}

\section{Elastic Moduli and Mechanical Rupture}

Whatever the goal of the aerogel synthesis, it is important to know how the supercritical drying (SD) can modify the physical and chemical features of the parent alcogel. The object of this part is to characterize the evolution of the mechanical properties. We will study the influence of synthesis parameters such as the concentration of gelifying precursors, $\mathrm{pH}$ of the hydrolysis solution and aging, on the physicochemical transformations observed during the supercritical fluid extraction. In the literature, mechanical testing has been made either on alcogels (West et al. 1988; Zarzycki 1988; Scherer et al. 1988) or on aerogels (Calemczuck et al. 1987; Dumas et al. 1990; Woignier et al. 1988b; Gross and Fricke 1992; Woignier et al. 2009), and comparison of the two sets of data suggests that supercritical drying enhances the mechanical features of the samples (Hafidi-Alaoui et al. 2000). The application of linear elastic fracture mechanics to wet gels is questionable, because it is necessary to justify that the material has an elastic behavior and can be treated as a continuum. Scherer (1992) has discussed this problem and has shown that it seems reasonable to apply fracture mechanics, because the elastic region near the tip of the crack is much larger than the plastic deformation at the crack tip. As previously mentioned, the beam bending test yields different elastic moduli for alcogels $(G)$ and for aerogels $(E)$. If we want to follow the influence of SD on the mechanical features, the shear modulus has been measured on alcogels and rewetted aerogels. $G$ can also be calculated from $E$ and the Poisson's ratio $v$. The shear modulus is related to $E$ by $E=2(1+v) G$. The Poisson's ratio, measured by Brillouin scattering and sound velocity propagation, is close to 0.2 over the whole range of aerogel density and for different catalysts. In fact $G$ calculated from $E$ and $v$ and $G$ measured on rewetted aerogels give similar results (Woignier et al. 1992).

Fig. 1 shows the influence of SD on the mechanical properties $G$ and the mechanical strength $\sigma$ of a neutral set of samples. It is clear that $G$ and $\sigma$ increase by a factor of 10-20. The effect of concentration is also shown and obviously the mechanical properties improve with the TMOS concentration, over almost two 


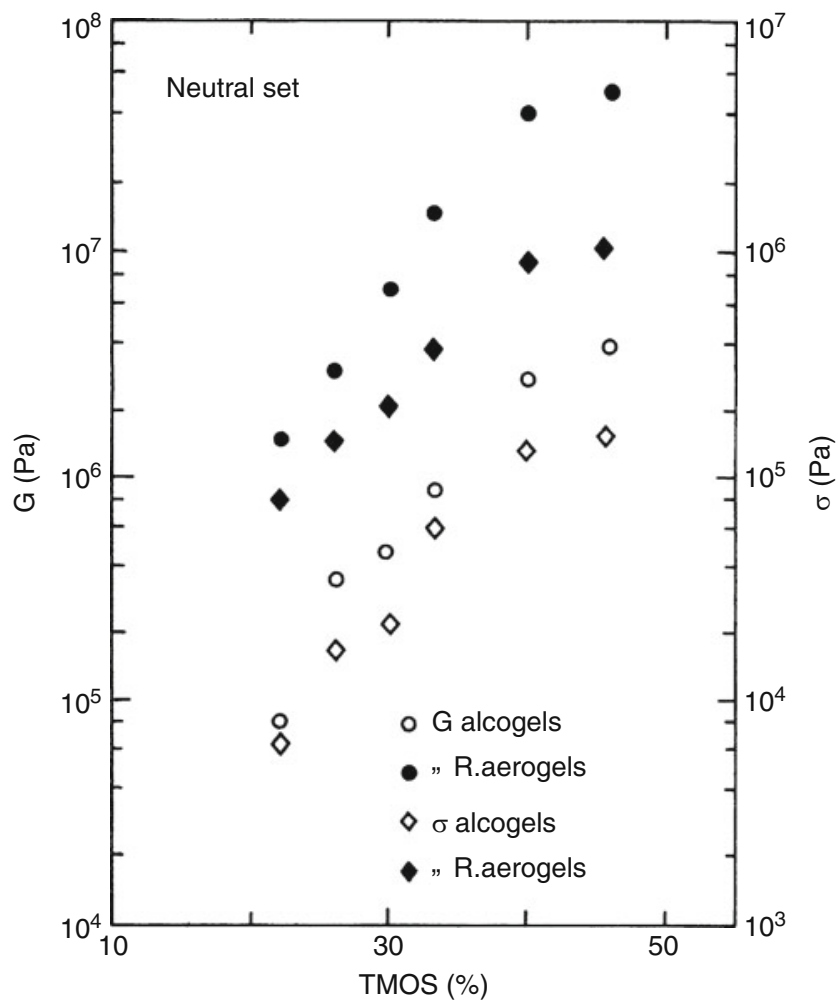

Fig. 1 Evolution of the elastic and mechanical properties $G$ and $\sigma$ as a function of the TMOS content for the neutral sets of alcogels and rewetted gels

orders of magnitude. However, during SD, a shrinkage is observed and the change of the mechanical properties could be attributed to this shrinkage, which increases the load-bearing fraction of solid. In Fig. 2, the shear modulus of the different sets of samples (neutral, basic, and acid) has been plotted as a function of the fraction of solids. $G$ values of rewetted aerogels are still higher by a factor of $4-5$. This figure shows also that, if the acidic and neutral samples have nearly the same mechanical properties, for the basic set, the values of $G$ are lower.

To explain the strengthening of the materials during SD, we can invoke two kinds of processes occurring in the autoclave. The first must be related to the formation of siloxane bonds between "dangling bonds" in the alcogel. These bonds contribute to the mass, but not to the connectivity of the network. When two branches come into contact, condensation reactions of silanol groups take place, increasing the connectivity. This process would increase the stiffness and the strength, but would also impose stresses on the alcogel network which could explain the shrinkage. The second mechanism of strengthening is due to the growth of the necks between particles. This growth occurs by a mechanism of dissolution-reprecipitation (driven 
Fig. 2 Evolution of $G$ as a function of the bulk density for neutral, acid, and basic sets of alcogels and rewetted gels

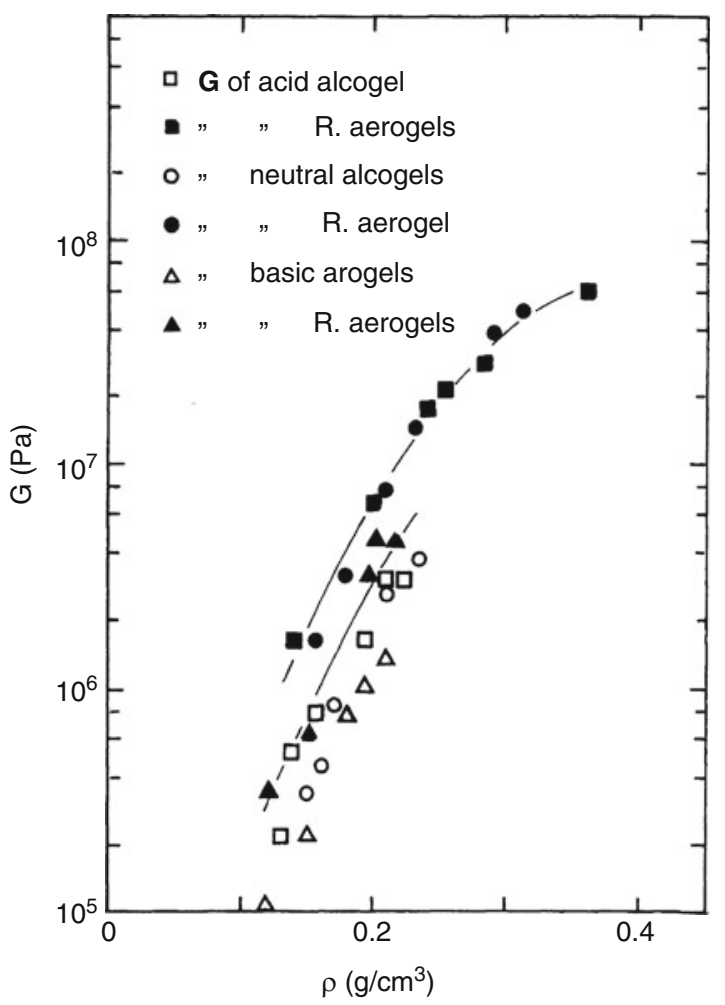

by a difference in solubility), which transfers silica from the particle surfaces to the necks. This process is accelerated by high temperature and pressure (Iler 1979).

In the case of acid and neutral sets which exhibit large shrinkages, the first mechanism is more likely. Acid gels are described as made of small primary particles, forming polymeric chains (Brinker and Scherer 1990). The flexibility of the chains allows contact and condensation reactions. For basic catalysis, the network is built of larger particles (Brinker and Scherer 1990) and the branched parts are more widely spaced, limiting the possibility of new bond formation by the first mechanism. For these reasons, we propose that the strengthening of the basic set is related to the second mechanism.

In Fig. 3, the effect of long aging times is shown. We observe that between 15 and 75 days, the samples continue to shrink slightly (the density increases), but the mechanical properties are almost constant. Contrary to a common belief, a very long aging is not a guarantee of gel strengthening. The curves obtained by SANS show the structural differences between aged (75 days) and unaged (1 day) aerogels (Fig. 4). The principal parameter that we can derive from the SANS curves is the fractal dimension, $D_{\mathrm{f}}$, which is related to the mass distribution in the cluster. $D_{\mathrm{f}}$ is calculated from the slope of the linear part. The size of the fractal cluster $(\xi)$ and of the elementary particles $(a)$ which built the cluster can be estimated from the two 


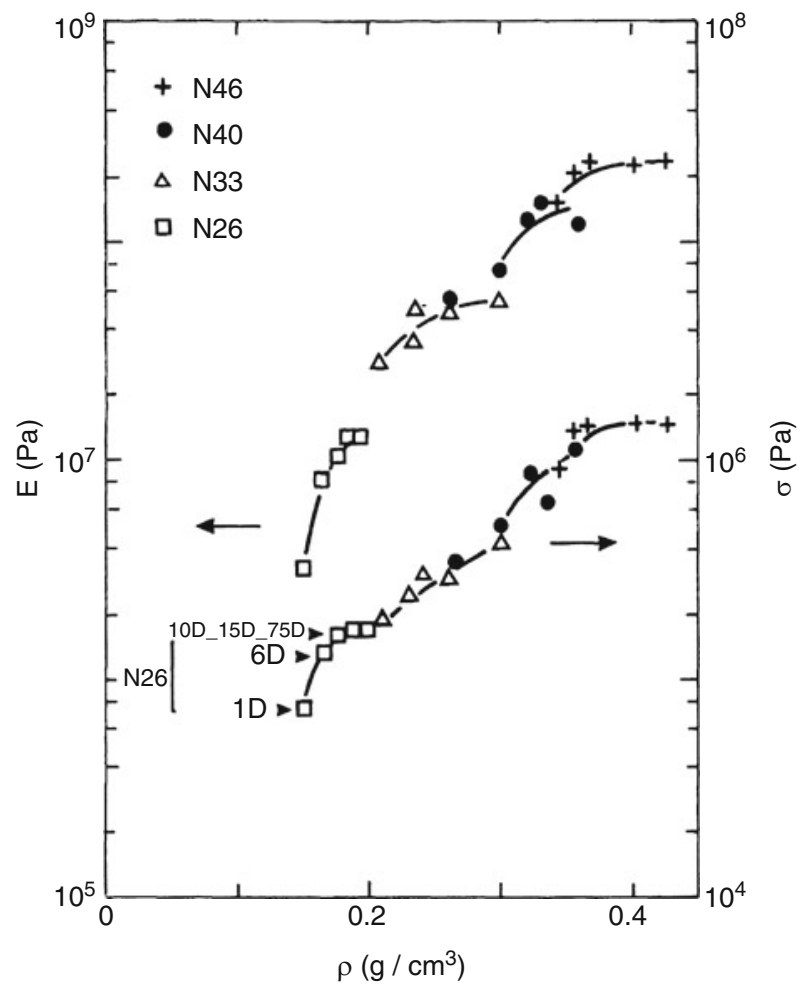

Fig. 3 Evolution of $E$ and $\sigma$ as a function of the bulk density and aging, for the neutral aerogels. N26, N33, N40, and N46 correspond, respectively, to aerogels with 26, 33, 40, and 46 TMOS weight percent. 1D, 6D, 15D, and 75D correspond, respectively, to 1 day, 6 days, 15 days, and 75 days of aging

crossovers at low and high $q$ [19]. For different samples, the fractal range $\xi / a$ is strongly reduced both by the decrease of $\xi$ and the increase of $a$. If we compare the effects of increasing concentration of TMOS and a longer aging, the effects on $\xi$ and $a$ are not identical. Both parameters decrease the fractal range $\xi / a$, but the decrease in $\xi$ is more pronounced by the effect of concentration and a long aging leads to the growth of $a$. As the decrease in $\xi$ corresponds to a lower macroporous volume and the growth of $a$ to the elimination of the microporosity, we will see later that these two factors have different influences on the mechanical properties.

\section{Toughness and Critical Flaw Size}

For brittle materials, the mechanical strength $\left(\sigma_{\mathrm{R}}\right)$ is strongly dependent on the presence of flaws, which act as stress concentrators (Griffith 1920). The most relevant feature of brittle materials is the toughness $\left(K_{\mathrm{IC}}\right)$, which characterizes the 
Fig. 4 Evolution of SANS curves, as a function of aging, for the neutral aerogels

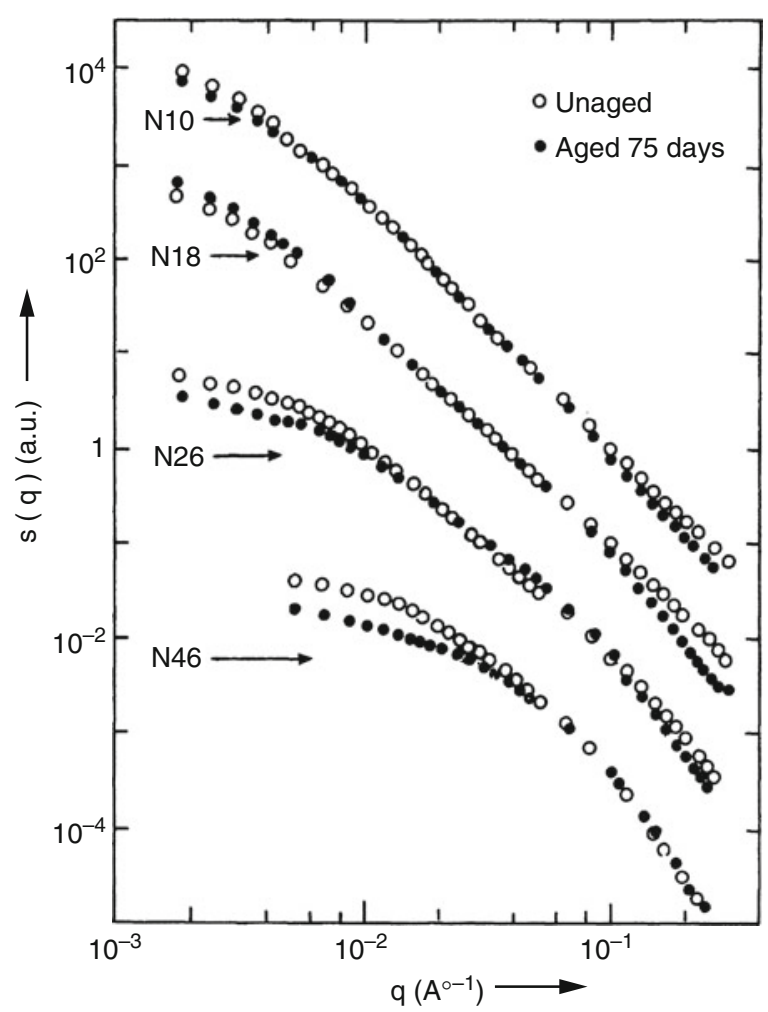

ability of the material to resist the propagation of flaw. Pores could be considered as flaws or as integral parts of flaw responsible for the failure of this brittle material. If such an assumption is valid, the critical flaw size should depend on the porosity and pore size (Hafidi-Alaoui et al. 2000). Then, we have measured the toughness for alcogels and aerogels with different porosities in order to analyze the toughness evolution during the alcogel-aerogel transformation. The critical flaw size, $a_{\mathrm{C}}$, will be derived from $K_{\mathrm{IC}}$ data and discussed in terms of pore size evolution.

Figure 5a, b shows the evolution of $K_{\mathrm{IC}}$ for the two sets of materials (basic and neutral) as a function of the TMOS vol\%. This figure also shows the toughness change upon supercritical drying. $K_{\mathrm{IC}}$ increases by a factor of 10 over the TMOS concentration range. The toughening of the two sets of materials is directly related to the decrease of pore volume. But clearly, the reported values are $10^{-3}$ lower than those measured on dense silica glass $\left(0.7-0.8 \mathrm{MPa} \times \mathrm{m}^{1 / 2}\right)($ Chermant et al. 1980).

Taking into account the textural and structural transformations of a gel during SD, a toughness increase is expected. Figure 5 confirms this assumption and the toughening by a factor close to 2 is observed for the two types of samples. Toughening is attributed to the syneresis effect and to the growth of necks between particles. 
Fig. 5 Evolution of $K_{\mathrm{IC}}$ as a function of TMOS content:

(a) for the basic alcogels and aerogels and (b) for the neutral alcogels and aerogels
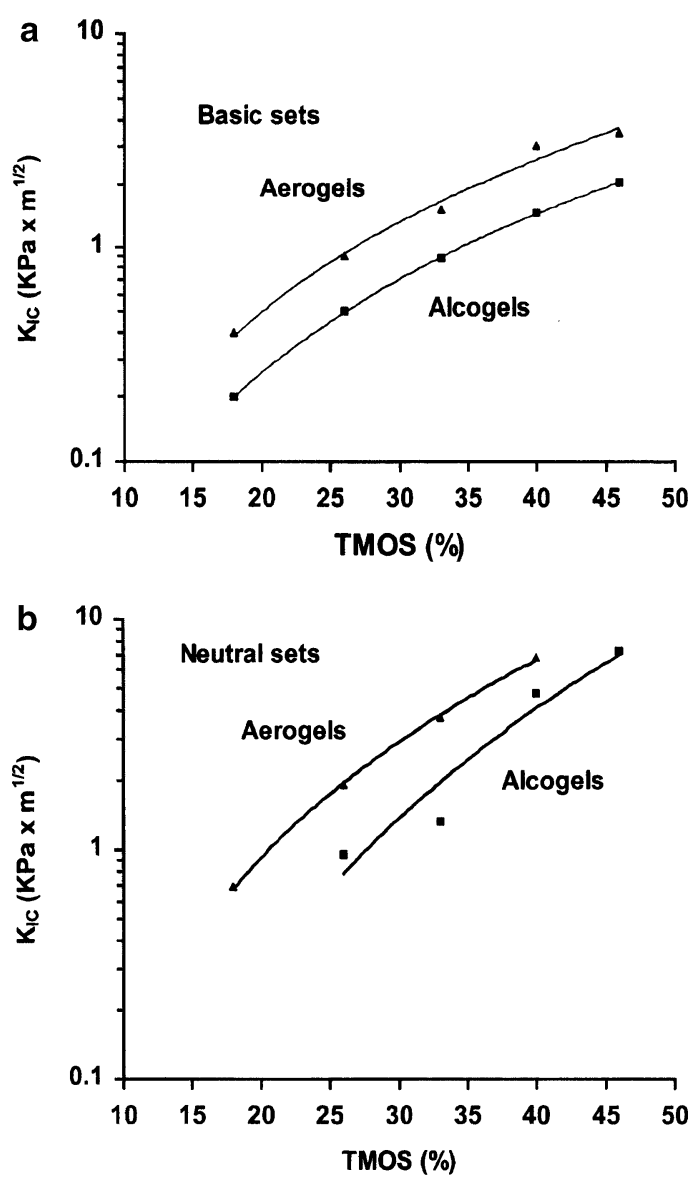

The knowledge of $K_{\mathrm{IC}}$ and $\sigma_{\mathrm{R}}$ allows one to calculate the critical flaw size, $a_{\mathrm{C}}$ (Evans and Tappin 1972). Assuming a Griffith flaw (as for silica glass), the critical size of the fracture initiating flaw may be obtained from $a_{\mathrm{C}}=1 / 1.21 \pi\left(K_{\mathrm{IC}} / \sigma\right)^{2}$. The $a_{\mathrm{C}}$ evolution as a function of the TMOS\% is reported in Fig. $6 \mathrm{a}, \mathrm{b}$. The $a_{\mathrm{C}}$ data range within 80 and $700 \mu \mathrm{m}$ and the general trend is an $a_{\mathrm{C}}$ decrease with the TMOS content and also during the supercritical drying. The comparison between the two kinds of catalysts (basic and neutral) shows that the $a_{\mathrm{C}}$ values for the neutral set are much more affected by SD.

A correlation could exist between $a_{\mathrm{C}}$ and the evolution of the pore size. The total porous volume in a gel consists of the macroporosity $(R>50 \mathrm{~nm})$, the mesoporosity $(R=2-50 \mathrm{~nm})$, and the microporosity $(R<2 \mathrm{~nm})$. A previous study (Pauthe 1991) has shown that, for the two sets of material (alcogel and aerogel), the microporous and mesoporous volumes are not strongly affected by the TMOS\%. On the other 
Fig. 6 Evolution of $a_{\mathrm{C}}$ as a function of TMOS content:

(a) for the basic alcogels and aerogels and (b) for the neutral alcogels and aerogels
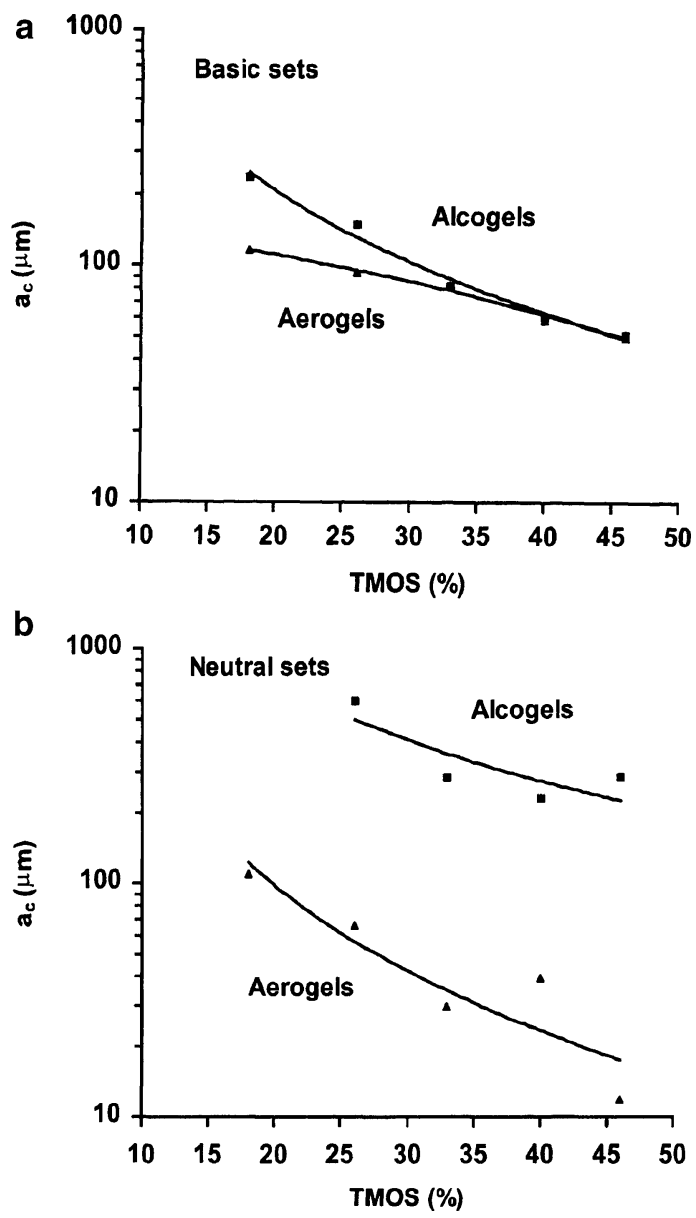

Table 1 Macro-, meso-, and micropore volumes for alcogels and aerogels

\begin{tabular}{l|l|l|l|l|l|l|l|l}
\hline & \multicolumn{9}{l}{ Alcogel } & \multicolumn{2}{l}{ Aerogel } \\
\cline { 2 - 10 } & N26 & N33 & N40 & B33 & N26 & N33 & N40 & B33 \\
\hline Vmacro (mm3/g) & 5610 & 4850 & 3720 & 4380 & 2590 & 780 & 380 & 3840 \\
\hline Vmeso (mm3/g) & 430 & 420 & 460 & 1750 & 2460 & 2720 & 2290 & 2320 \\
\hline Vmicro (mm3/g) & 125 & 100 & 80 & 80 & 0 & 0 & 0 & 0 \\
\hline
\end{tabular}

hand, the macroporous volume decreases strongly and the pore size distribution changes. The micropores disappear and the mesoporous volume increases at the expense of the macroporous volume (Table 1). This transformation is related to the syneresis process, shrinkage, and dissolution-reprecipitation of silica, favored by the supercritical treatment conditions (high pressure and temperature). 
The $a_{c}$ values suggest that, during $\mathrm{SD}$, the critical flaw size decreases. This can be associated to the transformation occurring during the autoclave treatment, which produces both a macroscopic shrinkage of the material and the evolution of the pore size distribution (Table 1). Consequently the pore could be considered as flaw or as an integral part of flaw responsible for the failure.

For the different parameters studied (TMOS\%, catalyst, SD), $a_{\mathrm{C}}$ decreases with the macropore size. We note that the $a_{\mathrm{C}}$ values are much larger than the pore size, so the scale of critical crack extends on a large number of pores. To satisfy this statement, it is necessary to consider that the flaws, which lead to failure, might be created during the test. We can suppose that the failure occurs by progressively breaking bonds, following the minimum solid area and collapsing a large number of pores located between "clusters." The macropores link into a macroscopic flaw and catastrophic failure occurs, when the size of the flaw becomes critical.

These $a_{\mathrm{C}}$ values suggest that, during the supercritical drying, the flaw size changes due to the thermal treatment and the resulting shrinkage. However, if this assumption is valid, the flaw size distribution could be modified and the Weibull modulus $(m)$, which characterizes the width of the distribution, has every chance to change. The goal of the next section is to determine the Weibull parameters of both sets of gels, alcogels and aerogels.

\section{Weibull Statistics}

In Weibull statistics, the failure probability function, $P(\sigma)$ is given as

$$
P(\sigma)=1-\exp \left[-\int_{V \text { or } S}\left(\frac{\sigma}{\sigma_{0}}\right)^{m} d V \text { or } d S\right]
$$

where $m$ is the shape parameter (Weibull modulus), $\sigma_{0}$ is the scale parameter (a normalizing constant), and the integral is taken over the volume $(V)$ or surface $(S)$ under tension.

When all the specimens have the same volume, the expression can be simplified (Sullivan and Lauzon 1986), resulting in

$$
P(\sigma)=1-\exp \left[-\left(\frac{\sigma}{\sigma_{0}}\right)^{m}\right]
$$

The analysis consists of converting a set of fracture stresses into an experimental probability distribution. This is done by arranging the results, from the lowest fracture stress to the highest. The $j$ th result in a set of $N$ specimens is assigned a cumulative probability of failure $P_{j}$. The estimator is chosen as

$$
P_{j}=\frac{j-0.5}{N}
$$




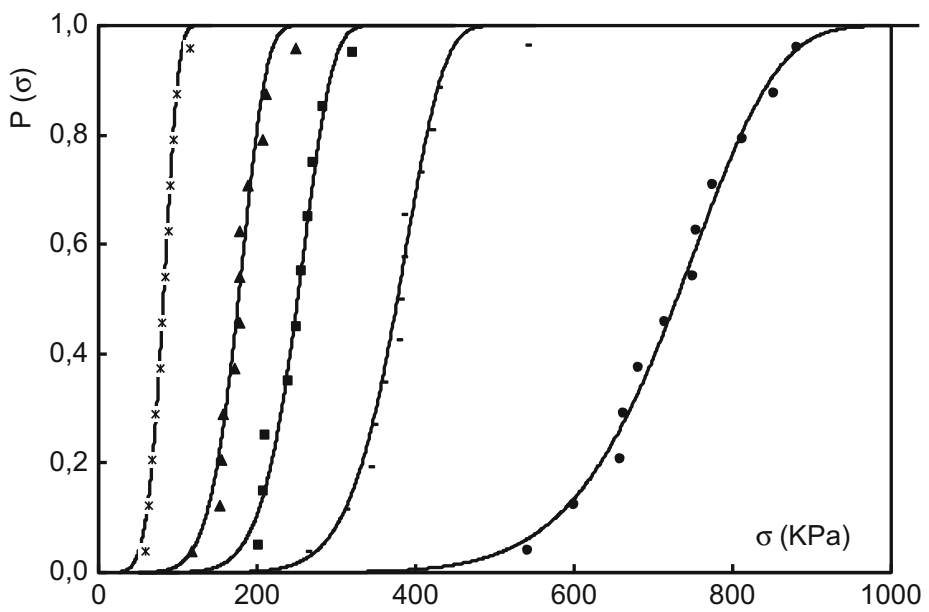

Fig. 7 Experimental and calculated cumulated failure probability distribution function, from left to right $(\mathrm{N} 18, \mathrm{x}, \mathrm{N} 26, \mathbf{\Lambda}, \mathrm{N} 33, \boldsymbol{\square}, \mathrm{N} 40,-$, and N46, )

Table 2 Weibull parameters for different aerogels

\begin{tabular}{l|l|l|l|l|l}
\hline Sample & $\mathrm{N} 18$ & $\mathrm{~N} 26$ & $\mathrm{~N} 33$ & $\mathrm{~N} 40$ & $\mathrm{~N} 46$ \\
\hline $\mathrm{m}$ & 4 & $5 \pm 0.5$ & $5.5 \pm 0.5$ & $6 \pm 0.5$ & $7 \pm 0.5$ \\
\hline$\sigma_{0}$ & 80 & 175. & 380 & 500. & 720. \\
\hline
\end{tabular}

which already allows a good determination of the $\mathrm{m}$ value, for sets within the range 20-30 specimens. Sets of 25 specimens (for each type of material tested, alcogels and aerogels) have been studied. Weibull modulus $(m)$ and scale parameter $\left(\sigma_{0}\right)$ values were derived from the calculations with $90 \%$ confidence limit.

Figure 7 shows the large scattering in the data due to the statistical nature of the mechanical strengths. On this figure is reported the experimental and calculated cumulated failure probability distribution function using the Weibull statistical analysis.

The small value of $m$ (Table 2) is characteristic of the wide distribution of the strength. While $\mathrm{m}$ varies slightly, $\sigma_{0}$ increases with TMOS $\%$. These results show that critical flaw sizes are probably less dispersed for aerogels with higher TMOS content which corresponds to aerogels with a narrow pore size distribution. Weibull modulus $(\mathrm{m})$ and $\sigma_{0}$ deduced from the calculations for the different aerogels are plotted in Table 2.

For the alcogel sets (Table 3), the smaller value of $m$ is a characteristic of a wider distribution of strengths, $m$, and $\sigma_{0}$ increases with SD. These results show that critical flaw sizes are more dispersed for alcogels than for aerogels and confirm the strengthening of the structure attributed to the polycondensation of "dangling bonds." 
Table 3 Weibull parameters for alcogels and aerogels

\begin{tabular}{l|l|l}
\hline Sample & $m$ & $\sigma_{0}(\mathrm{KPa})$ \\
\hline Alcogel N40 & $5.0 \pm 0.4$ & $210 \pm 2$ \\
\hline Aerogel N40 & $5.9 \pm 0.6$ & $500 \pm 5$ \\
\hline Alcogel B40 & $5.1 \pm 0.5$ & $120 \pm 1$ \\
\hline Aerogel B40 & $6.4 \pm 0.6$ & $150 \pm 2$ \\
\hline Aerogel B40 Ox & $10 \pm 0.9$ & $180 \pm 2$ \\
\hline
\end{tabular}

Since the samples of both materials have approximately the same size, the probability of finding the largest flaw in the same effective volume decreases significantly from alcogels to aerogels. This result can rather be explained by the difference between their texture and particularly assuming that critical flaw is bound to the connectivity in both materials. Alcogels have a low connectivity as was shown previously; as a result, the probability of finding the weakest link in the stressed volume of alcogels is rather high.

The last line of Table 3 gives $m$ and $\sigma_{0}$ for a sample aerogel N40 after an oxidation heat treatment. The oxidation heat treatment replaces the organic groups (generally present at the surface of the solid phase) by $\mathrm{OH}$ groups; the surface becomes hydrophilic. The experimental results show a small increase of $\sigma_{0}$ and a large increase of $m$. This preliminary result shows the clear influence of the chemical nature of the solid surface, on the mechanical behavior of the gels. It is a good introduction to the "stress corrosion effect" developed in the following section.

\section{Stress Corrosion}

We have stated that careful drying and, specially, supercritical drying allow the preparation of large monolithic gels. However, several months after drying some of the gels and aerogels can crack without any stress applied. A first analysis shows that the reason of these cracks could be the "stress corrosion effect." This phenomenon is well known in the case of glasses, which can crack under a constant stress lower than the mechanical resistance. It is due to the joint effect of a stress and a corrosion mechanism at the tip of the flaws, by chemical species such as water or alcohol. It is known that the strength and fatigue lifetime of vitreous silica decrease in humid environments (Michalske and Freiman 1983). In the case of gels and aerogels, the internal stresses coming from the shrinkage, the syneresis, and/or the thermal treatment would be responsible for this effect. Moreover, the stress corrosion induced by the supercritical fluid could also explain some cracking in the autoclave (Woignier et al. 1994). Understanding the whole fracture behavior of silica gels implies the study of the stress corrosion effect, because mechanical fatigue will limit their technological applications if the materials are under stress (Crichton et al. 1999; Woignier et al. 2009).

The objective of this section is to give additional information to confirm this hypothesis. One of the important corrosion parameters is the stress corrosion 
susceptibility factor, $n$. The exponent $n$ characterizes the evolution of the crack velocity as a function of the stress intensity factor. It is determined by fatigue experiments, under the corrosive environment of interest (Despetis et al. 2004).

We have shown that failure is the result of the stress concentration at the flaw tip. When stressed, a brittle material is characterized by a given value of the stress intensity factor $K_{\mathrm{I}}$. Fracture occurs when either the applied stress or the flaw length or both increase in such a way that $K_{\mathrm{I}}$ reaches the value, $K_{\mathrm{IC}}$ (the critical stress intensity factor or fracture toughness). However, under a corrosive environment, the flaw can grow with time at a rate usually expressed by the following empirical relationship (Evans 1974):

$$
V=A K_{\mathrm{I}}^{n}
$$

where $A$ and $n$ are constants and $n$ is the stress corrosion susceptibility factor.

Figure 8 shows the evolution of the crack velocity as a function of the stress intensity factor for two kinds of aerogels (as prepared and oxidized). As explained below, the main difference between these two aerogels is the groups bonded to the surface. The surface of the as-prepared aerogels is covered by organic groups which are replaced by $\mathrm{OH}$ groups after the oxidation heat treatment. We can say that these porous silica networks are identical except for their hydroxyl contents. At low $K_{\mathrm{I}}, V$ is two orders of magnitude higher for the hydrophilic gel. We note that $n$ is identical in this $K_{\mathrm{I}}$ range for the two samples, which means that the mechanism associated to crack propagation is the same; $n$ is close to 15 and corresponds to a corrosion mechanism by $\mathrm{OH}^{-}$(Despetis et al. 2001). At higher $K_{\mathrm{I}}, n$ changes and becomes equal to 35 , the classical $n$ value found for vitreous silica, associated to a corrosion mechanism by water molecules (Suratwala and Steele 2003). To explain crack

Fig. 8 Evolution of the crack velocity as a function of the stress intensity factor, for as-prepared and oxidized aerogel

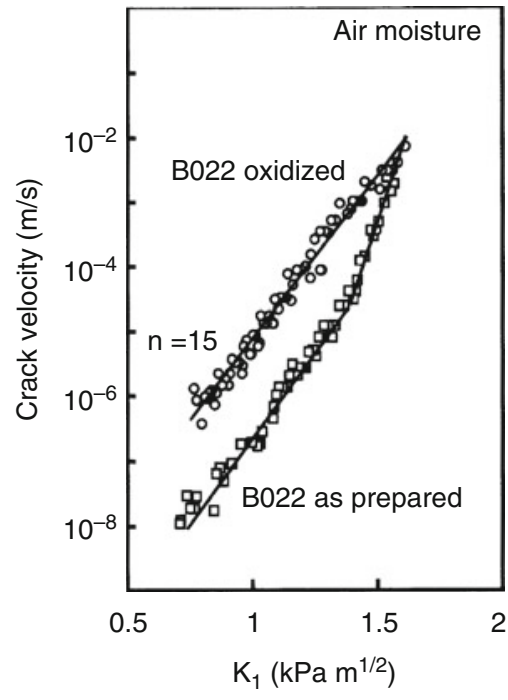


growth in dense silica under air moisture, it was assumed that water molecules close to a strained siloxane bond transform the bridging oxygen in two silanol bonds. The difference in crack velocity between hydrophobic and oxidized aerogels is related to the surrounding chemical species. For hydrophilic aerogels, the pores are covered by $\mathrm{OH}$ groups and highly structured water molecules, which play the role of a basic catalyst. In the case of hydrophobic materials, $\mathrm{OH}$ groups are fewer and the hydrolysis is screened by the presence of organic groups. Because hydrophobic aerogel surfaces have a lower relative humidity, basicity is low and the crack propagation is slower. These results put in evidence the influence of the gel $\mathrm{OH}$ content of the gel on its mechanical behavior. Because of the stress corrosion effect, a monolithic gel can crack several days or months later, even under a low stress (e.g., an internal stress), if its $\mathrm{OH}$ content favors the progressive hydrolysis of the siloxane bonds leading to the formation of a critical flaw.

\section{Aerogel to Glass Transformation}

\section{Sintering}

Aerogels are easily transformed into dense silica glass by oxidation and sintering (Woignier et al. 1990, 2011). During these treatments, the structure of the aerogel is modified and the mechanical properties are improved (Phalippou et al. 2004).

Figure $9 \mathrm{a}, \mathrm{b}$ shows the evolution on a $\log -\log$ plot, of Young's modulus $(E)$, the fracture strength $(\sigma)$, and the toughness, $K_{\mathrm{IC}}$, as a function of the density, produced
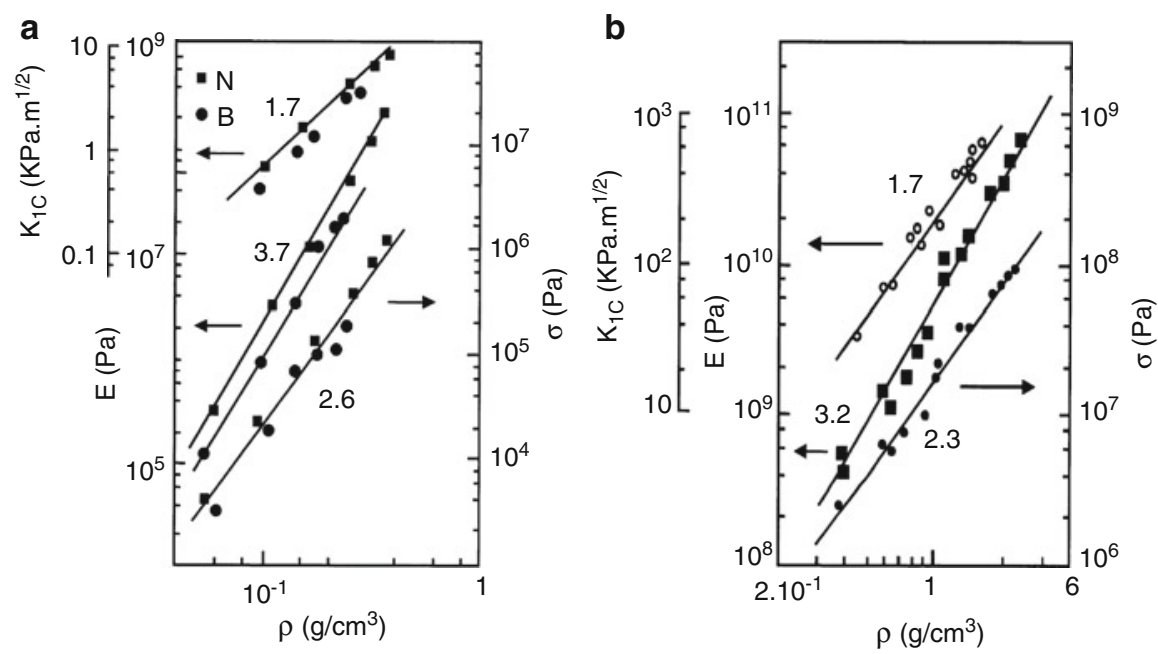

Fig. 9 Evolution of the elastic and mechanical properties $E, \sigma$, and $K_{\mathrm{IC}}$ as a function of the bulk density (a) for the neutral and base-catalyzed gels and (b) for sintered gels 
by different kinds of catalyst (Fig. 9a) and by sintering (Fig. 9b). The two sets of materials, aerogels and Partially Dense Aerogels (PDA), cover the whole range of porosity. During sintering, the PDA strengthens and finally the mechanical features of the fully dense material are identical to those of conventional silica glass. The strengthening of the material is directly related to the decrease of pore volume, but also, at a given density, to the increase of the connectivity of the network. During the oxidizing and sintering treatments, organic species and silanol groups are replaced by siloxane bonds, increasing the connectivity and thus improving the mechanical properties. The two sets of curves show also the power law dependence, with exponents 3.2-3.7, 2.3-2.6, and 1.7, respectively, for $E, \sigma$, and $K_{\mathrm{IC}}$. Figure 10 shows the evolution of the critical flaw size as a function of the bulk density, for the sintered aerogels. It appears that $a_{\mathrm{C}}$ is within the range of 5-100 $\mu \mathrm{m}$ and decreases over the bulk density range. In Fig. 10, it is also plotted the evolution of the larger pore size (LPS), measured on the sintered material by porosimetry (Beurroies 1995; Woignier et al. 1994). In the first part, we have shown that, during supercritical drying, the $a_{\mathrm{C}}$ evolution can be associated to transformations occurring in the autoclave: a macroporous volume decrease and a decrease of the mean pore size. It has been shown that $a_{\mathrm{C}}$ follows the size change of the largest pores (macropores). For all the parameters studied (TMOS\%, catalyst, supercritical drying), the critical flaw size decreases with the macroporous volume. During sintering the macroporous volume is progressively reduced and, when all the macropores have disappeared, the largest mesopores begin to collapse. Like during supercritical drying, we can associate the $a_{\mathrm{C}}$ decrease during sintering to the larger pore size (LPS) and macroporous volume decrease. As already mentioned, the $a_{\mathrm{C}}$ values are much larger than the pore size, so the scale of critical crack extends over a large number of pores. The failure occurs by bond breaking, collapsing a large number of pores.

Fig. 10 Evolution of critical flaw size $\left(a_{\mathrm{C}}\right)$ and the larger pore size $(L P S)$, as a function of the bulk density, for sintered gels

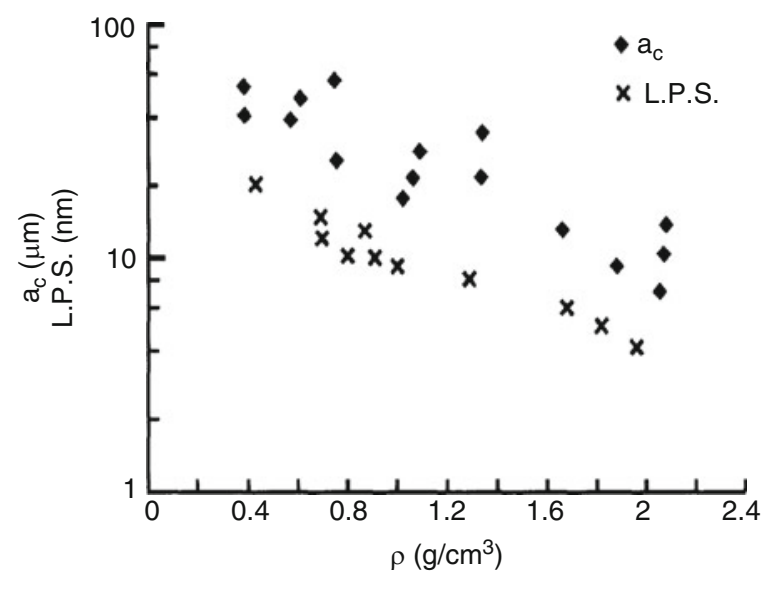




\section{Plastic Densification in Silica Aerogels}

In the preceding section, silica gels are described as purely elastic materials and the stress-strain relation evolves like for a common elastic material toward a "catastrophic" fracture. No plastic deformation has been reported, when a gel is subjected to a tensile load. However, previous works (Pirard et al. 1995; Scherer et al. 1995; Duffours et al. 1995) have shown that if an aerogel is subjected to a compressive load, the solid network initially behaves elastically, until the strain is no longer proportional to the stress. After the stress release, an irreversible strain is observed, characteristic of a plastic behavior. The yield stress and the magnitude of the plastic shrinkage are strongly dependent on the textural and structural features of the silica aerogel (Duffours et al. 1995; Woignier et al. 2010). Owing to the plastic shrinkage, the material shrinks progressively by pore collapse and volumic shrinkage higher than $50 \%$ can be observed. Obviously, one is tempted to draw a parallel between this densification process and the high temperature sintering mechanism which also leads to pore elimination. Moreover, this unexpected result should be explained, in order to understand the whole mechanical behavior of the gels. In this section, this plastic shrinkage is investigated and its mechanism is compared to that of viscous flow sintering. Two kinds of information will be analyzed: the evolution of the elastic properties, due to plastic shrinkage (or sintering), and the associated structural changes by small-angle X-ray scattering. The elastic properties will give insight into the evolution of the connectivity, and the X-ray scattering data will help quantify the eventual transformation of the cluster, internal compactness (fractal dimension), and size of the constitutive particles.

Figure 11 shows the response behavior of a compliant gel, during a compression run. If the applied pressure is lower than the yield strength, the sample deforms elastically; the volume strain is proportional to the stress applied and, after the pressure release, the sample recovers its initial volume. When the pressure applied is higher than the yield strength $(\approx 10 \mathrm{MPa}$ in this case), the behavior is no longer elastic and a part of the volume strain is irreversible. Thus, as a function of the pressure applied during the run, the sample bulk density increases. Macroscopically, pressure and temperature apparently result in the same effect; they induce pore collapse and a density increase. Generally, such a densification is accompanied by a stiffening of the solid and the elastic properties of the porous material improve with the bulk density.

Figure 12 shows that the elastic longitudinal modulus $H$ (calculated from the sound velocity, $V: H=\rho \mathrm{V}^{2}$ ), plotted as a function of the bulk density, exhibits two different behaviors. For the PDA set, the sintering is accompanied by stiffening of the material, the sample of $0.55 \mathrm{~g} / \mathrm{cm}^{3}$ being 10 times stiffer than the one of $0.33 \mathrm{~g} / \mathrm{cm}^{3}$. On the other hand, the PCA set shows a lowering of the elastic modulus $H$, between 0.33 and $0.45 \mathrm{~g} / \mathrm{cm}^{3}$, characterizing a loss in the network connectivity. In the second part of the curve, the PCA set shows an increase of $H$ above $\rho \approx 0.5 \mathrm{~g} / \mathrm{cm}^{3}$ leading to the conclusion that after the connectivity loss, compression induces the formation of siloxane bonds. 


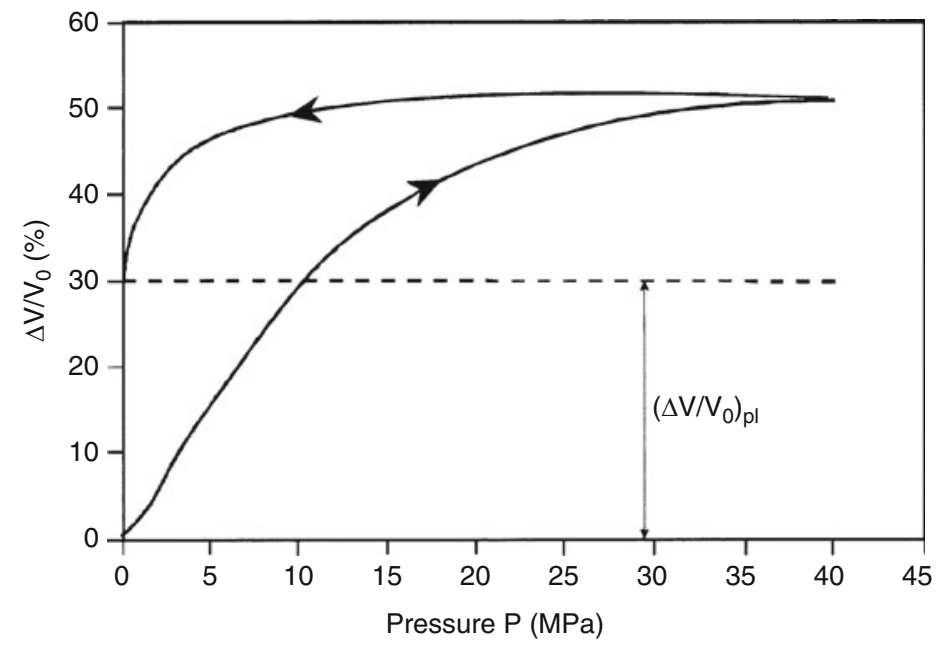

Fig. 11 Typical volume strain $\left(\Delta \mathrm{V} / \mathrm{V}_{0}\right)$ versus applied pressure curves

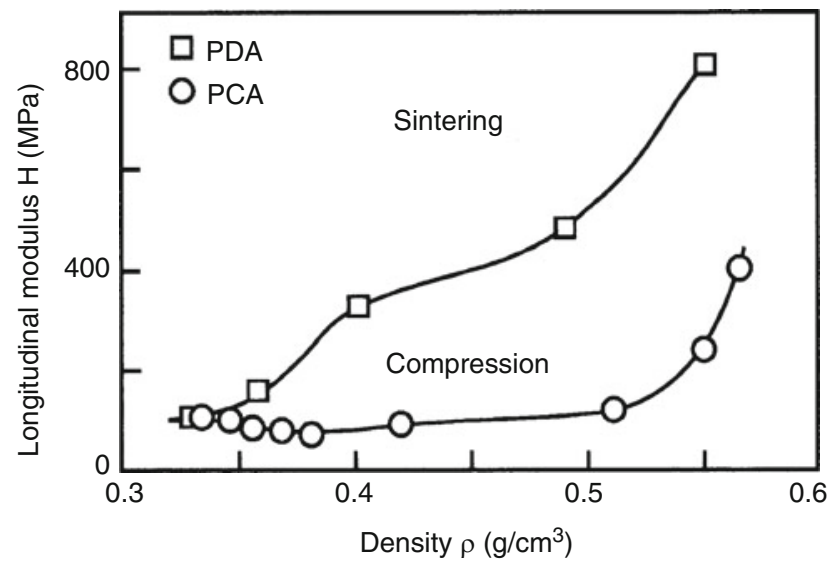

Fig. 12 Evolution of the longitudinal elastic modulus $\mathrm{H}$, as a function of the bulk density, for sintered and compressed gels

The structural details obtained by small-angle X-ray scattering are used to follow the respective structural evolution of the PDA and PCA sets (Fig. 13a-c). During sintering the fractal dimension and the particle size increase, while the compression runs do not significantly change $D_{\mathrm{f}}$ or $a$. On the other hand, the cluster size is more affected by compression than by sintering. The interpretation of SAXS data suggests that, for sintered samples, the densification is induced by viscous flow, which tends to contract the clusters and consequently reduces the whole sample volume. The 
a

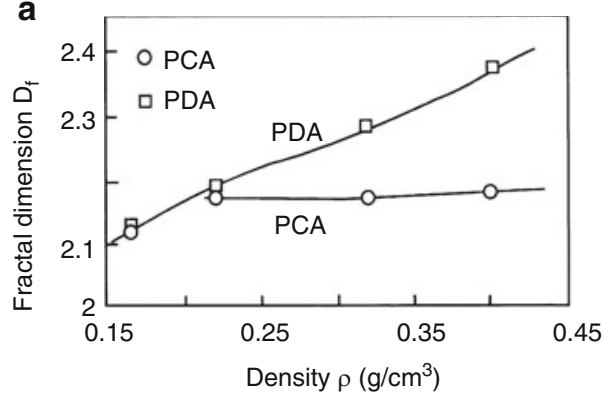

b

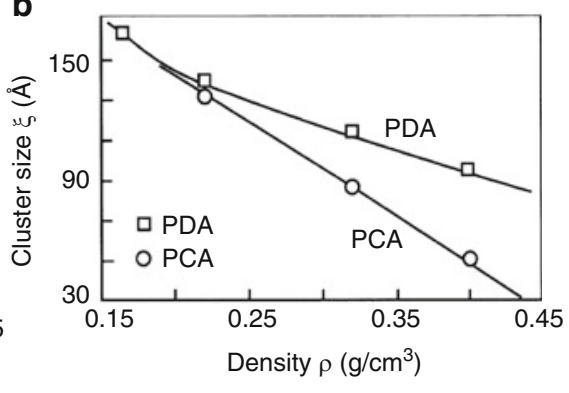

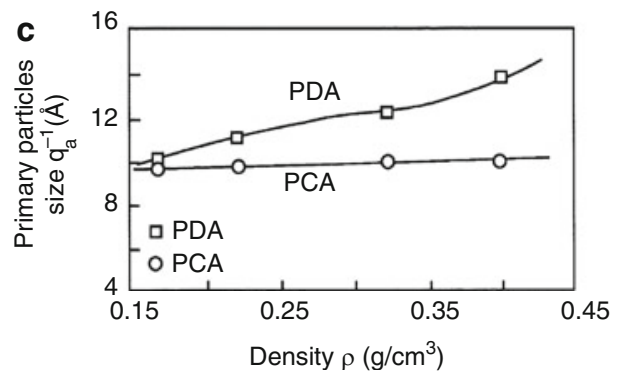

Fig. 13 Evolution of structural features: (a) fractal dimension, (b) cluster size, (c) particle size, as a function of the bulk density for sintered and compressed gels

densification proceeds by coalescence of small particles into larger ones. $D_{\mathrm{f}}$ tends toward 3, indicating cluster densification related to particle coalescence. The local sintering has two effects: it pulls the network, shrinking the clusters, and it increases the connectivity in the whole material.

On the other hand, in the case of densification by compression, the main restructuring is due to a new spatial arrangement of the clusters. The clusters interpenetrate each other, their periphery is changed, but their internal structure is not affected. This indicates that the pore volume between clusters is reduced. This rearrangement is reasonable, taking into account the process which stresses the samples by isostatic external pressure. During compression, because the solid is not viscous, such a restructuring should induce important strain and local disconnection in the network.

To allow the motion of the clusters, a part of the links at the boundaries between aggregates should be broken and the whole connectivity of the network is lowered. However, because the clusters touch and interpenetrate, silanol groups $(\mathrm{SiOH})$ can polycondense and the formation of siloxane bonds would increase the network connectivity. These two opposing effects, breakage and formation of links, occur simultaneously. These assumptions explain the $H$ changes observed in Fig. 12.

To check if the plastic shrinkage is also due to the formation of siloxane, Fig. 14 compares the shrinkage measured on as-received basic material and oxidized basic material (large $\mathrm{OH}$ content). These two samples have same bulk density and pore size distribution but differ by the $\mathrm{OH}$ content. As expected, the $\mathrm{OH}$ content favors 


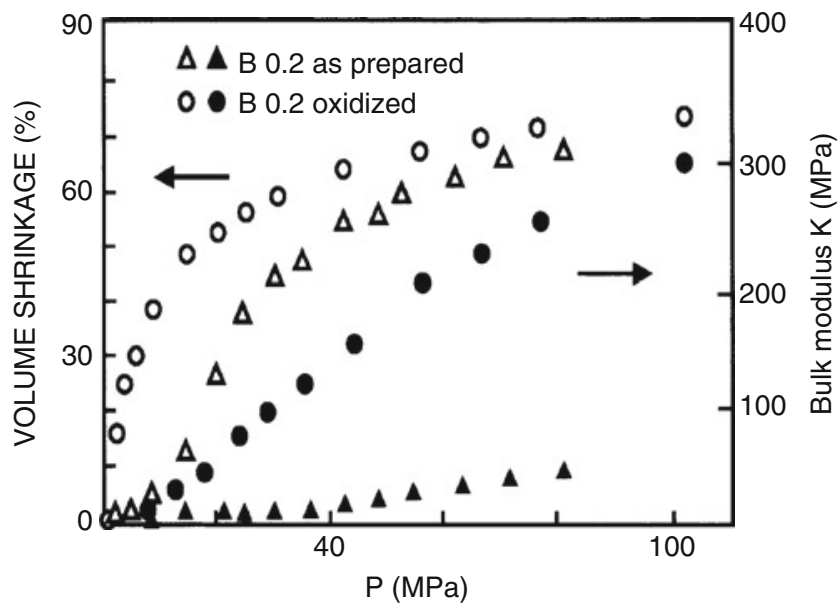

Fig. 14 Plastic shrinkage $\left(\Delta \mathrm{V} / \mathrm{V}_{0}\right)_{\mathrm{pl}}$ and bulk modulus, versus pressure, for as-prepared and oxidized aerogels

clearly the shrinkage at low pressure. In oxidized samples, the clusters are chemically active. They may react if silanol groups are close enough to condense, leading to freezing of the strained structure.

To confirm this effect, on the same figure is also reported the elastic bulk modulus of the compressed material, as a function the pressure. The large amount of $\mathrm{SiOH}$ in the oxidized samples favors the formation of siloxane bonds and stiffens the network. A further shrinkage is then more difficult. The change in network connectivity (measured by the $K$ evolution) is the result of the competition between two opposite mechanisms: the breakage of siloxane bonds and the formation of links by silanol condensation. For as-prepared aerogels, densification is due to the action of pressure, which forces clusters to interpenetrate, but only a few siloxane bonds are created. On the other hand, for oxidized samples, because of the large silanol content, the formation of new siloxane bonds largely compensates the cleavage of a part of them.

\section{Models}

In the literature, many empirical relationships have been used to relate elastic and mechanical properties to porosity of brittle solids. However, these relationships are generally valid for a restricted range of porosity and their exponent is empirical and depends on the nature of the solid phase.

Different approaches (cellular models, percolation analogy, fractal structure, blobs and links) have also been proposed, to account for the porous volume and calculate the evolution of the mechanical properties as a function of the structural 
characteristics. Such models seem attractive to describe the mechanical properties of gels for several reasons. In contrast with the empirical relationships, they try to relate the physical properties to a description of the mean structure or to the aggregation process; they also predict that the Poisson ratio is constant with the fraction of the solid phase, which is an experimental result demonstrated for aerogels and PDA. Another interesting feature of those models is that they predict a power law evolution of the mechanical properties as a function of the fraction of solid phase, and the $\log -\log$ plot of Fig. 8a, b demonstrates such a behavior for $E$ (and for $G$ ), $\sigma$, and $K_{\mathrm{IC}}$.

\section{Cellular Model}

In the cellular model (Gibson and Ashby 1988), the porous solid is defined as a material built up of struts or plates, which form the edges and the faces of the cells. The most important structural characteristic of the cellular models is their relative density, which can be expressed as a function of the cell edge length, $l$, and the size of the cross section, $t$. For an open-cell foam made of cubic polyhedra, $\rho / \rho_{\mathrm{s}}$ is proportional to $(t / l)^{2}$. Then, the elastic and the mechanical features have been calculated, respectively: $E \propto\left(\rho / \rho_{\mathrm{s}}\right)^{2}$ and $K_{\mathrm{lC}} \propto\left(\rho / \rho_{\mathrm{s}}\right)^{3 / 2}$.

The analysis of the results obtained with PDA shows that $E$ varies as $\left(\rho / \rho_{\mathrm{s}}\right)^{3.2}$ and $K_{\mathrm{IC}}$ as $\left(\rho / \rho_{\mathrm{s}}\right)^{1.7}$. To explain why the model fails, we have to consider that it assumes that all the solid phase is connected and participates in the load bearing. In fact, the bond area between particles is not taken into account and is an important parameter in the case of a real material. The mechanical properties of the PDA must be modeled by a cell having a lower $t / l$ value than those derived from $\rho / \rho_{\mathrm{s}}$. In fact, the material behaves as a cellular solid, with an effective bulk density lower than $\rho / \rho_{\mathrm{s}}$. The larger experimental scaling exponent can be explained if we consider that, during sintering, the effective bulk density increases rapidly by the elimination of porosity and increase of the bond area.

\section{Percolation Gelation Analogy}

To explain the power law evolution of the elastic modulus and the exponent a close to 4 , it has been proposed that an analogy could exist between a gel and a percolation cluster (Stauffer 1976). In this theory, elastic properties are expected to scale as $E \propto$ $\left(P-P_{\mathrm{C}}\right)^{\tau}$ where $P$ is the probability for a site to be occupied (or a bond to be created) and $P_{\mathrm{C}}$ is the percolation threshold (defined as the magnitude of $P$ above which an infinite cluster exists). Analytical work and simulations have calculated a critical exponent characteristic of the elastic modulus) and $\tau$ is close to 4 (Feng and Sen 1984; Kantor and Webman 1984).

Experimental studies on gels (Tokita et al. 1984; Adam et al. 1985) have been analyzed using this analogy. The most important difficulty arises from the choice of the physical variable which must be related to the unknown mathematical variable 
$\left(P-P_{\mathrm{C}}\right)$. Several variables, such as the concentration of monomer or density, have been proposed, assuming implicitly a proportionality between the variables and the $P$ scale.

In fact, in the straightforward gelation/percolation analogy, the gel fraction (and thus the density) is associated with the percolation probability, $\wp(P)$ (the probability for a site to belong to the infinite cluster) and scales with an exponent, $\beta: \rho \propto \wp(P) \propto$ $\left(P-P_{\mathrm{C}}\right)^{\beta}$, then $E \propto \rho^{\tau / \beta}$. The experimentally determined $\alpha$ in Fig. 8a, b would be $\tau /$ $\beta$. Using a $\beta$ value equal to 0.4 (the theoretical prediction in a three dimension model), we find that $\tau$ is equal to 1.5 , far from the predicted exponent.

\section{Fractal Dimension Approach}

Another approach found in the literature tries to relate the exponent, $\alpha$, to the fractal dimension of the network (Emmerling and Fricke 1997), and a relation is proposed:

$$
\alpha=\frac{5-D_{\mathrm{f}}}{3-D_{\mathrm{f}}}
$$

However, this approach is not valid for the complete sets of data in the literature. For example, it cannot explain why $\alpha$ in Fig. 8a is similar for the different sets of aerogels, $N$ or $B$, which have different fractal dimensions (2.4 and 1.8, respectively). Moreover, during sintering, $D_{\mathrm{f}}$ changes and tends toward 3 . The $\alpha$ value should increase between the aerogel sets and the sintered sets. Such an assumption disagrees with the results in Fig. 8a, b ( $\alpha$ decreases from 3.7 to 3.2). Finally, for samples having a density $>1$, the fractal description is meaningless, but, in the whole range of density of $0.4-2.2$, the $\log -\log$ plot still leads to an $\alpha$ close to 3.2 .

It is clear that the exponent value is not related to the fractal dimension and to percolation theory. The structure and the connections of a gel are the result of a sequence of different processes: gelation, aging, and shrinkage. The $\alpha$ value should describe the way the clusters are connected between them and not the structure inside the clusters.

\section{Blobs and Links}

In a more recent work (Ma et al. 2001), the authors proposed to use the diffusionlimited cluster-cluster aggregation (DLCA) algorithm, to generate 3-D lattice gels models. The bulk moduli were calculated by the finite element method and the result shows that DLCA models exhibit the same scaling relationship. However, the simulations indicated that $\alpha \approx 7.6$, overestimating the experimental data. The DLCA model contains excessive dangling bonds which lead to wrong estimation of the stiffness, and simulation shows that loops in the structure are important to account for the elastic behavior. 
A new algorithm called "dangling bond deflection" has been developed to transform the dangling bonds into loops. This algorithm simulates the motion of dangling bonds and the associated dangling branches. A bond is formed when a deflected dangling branch collides with another cluster and a loop is closed when the bonding particles belong to the same cluster.

The exponent $\alpha \approx 3.6$, calculated using this gel model, is in the range of $\alpha$ values observed in experiments. The compliant nature of aerogels is a result of the fact that stresses localizes on a few tenuous chains. Fewer bonds share the strain when density decreases, so the modulus of the network drops faster than for the cellular model. The structure generated by the combination of the DLCA and the dangling bond deflection algorithm can successfully reproduce the scaling relationship of aerogels.

More recently, Anez et al. (2010) introduce a method for a computational calculus of the elasticity modulus (E) of simulated porous media using the Monte Carlo technique. The porous media of known geometry is simulated as an elastic network of central forces, to which a known deformation is applied. The minimum strain energy is calculated by applying the Monte Carlo technique.

\section{Conclusion}

The mechanical behavior of common glasses has been analyzed for a long time and is now well known: they are described as brittle and elastic materials. But what about porous glasses? The general agreement is that porous glasses are brittle and elastic too, but the mechanical characteristics (strength, elastic constants, toughness) are lower, due to the pore volume and the associated lower connectivity of the network. The possibility to sinter gels and aerogels into dense silica glass allows us to follow the evolution of the mechanical properties over the whole range of porosity $99 \%$ to $0 \%$.

At each step of the process, the increase of the elastic moduli and mechanical properties is related to the gel structure and several mechanisms are involved. During supercritical drying, flexible dangling bonds can condense and form new links, but the increase of the mechanical properties is also due to a dissolution-reprecipitation phenomenon.

Because of their large pore volume, the mechanical properties of dried gels are several orders of magnitude lower than those of the dense silica, but the mechanical behavior seems identical to that of brittle materials like glasses. The bulk density is the main parameter which defines the elastic and brittle features, but two others parameters (pore size distribution and $\mathrm{OH}$ content) are also significant to describe and understand the whole mechanical behavior. Toughness measurements have shown that the flaw size responsible for fracture seems to be related to the size of the largest pores. Failure occurs by progressive breaking bonds collapsing a large number of pores. The macropores link into a macroscopic flaw and catastrophic failure occurs when the size of the flaw becomes critical. Moreover, the porous network is sensitive to the stress corrosion effect, which can lead to failure after 
several months, under a low stress (monolithic aerogels have cracked because of the internal stresses, only). This effect is favored by the $\mathrm{OH}$ content of the gel.

Besides the brittle elastic behavior, when a gel is subjected to a tensile load, under a compressive load, the porous network can be irreversibly transformed. This "plasticity" effect depends strongly on the volume fraction of pores, but is also clearly affected by macropores and by the $\mathrm{OH}$ content. In fact, either under tension or compression, the gel material is not stable and its structure and mechanical features evolve.

Extrapolation of the densification curves leads to the conclusion that dense glasses could be obtained by applying a pressure in the range 500-1000 MPa. This new densification process could be an interesting way to prepare glasses at room temperature.

Acknowledgments The authors would like to thank the editors of Journal of Non-Crystalline Solids, Journal of Sol-Gel Science and Technology and the European Physical Journal for their permission to publish figures here reported.

\section{References}

Adam M, Delsanti M, Durand D. Mechanical measurements in the reaction bath during polycondensation reaction near the gelation threshold. Macromolecules. 1985;18(11):2285-90.

Anez L, Primera J, Hasmy A, Fransceni P, Sanchez N, Woignier T. A method for elasticity modulus calculation in porous media using the Monte Carlo technique. Key Eng Mater. 2010;423:75-82.

Brinker CJ, Scherer GW. Sol-gel science. New York: Academic; 1990.

Calemczuck R, de Goer AM, Salce B, Maynard R, Zarembowitch A. Low temperature properties of silica aerogels. Europhys Lett. 1987;3(11):1205-11.

Chermant JL, Osterstock F, Vadam G. Etude critique de la mesure de Kic dans le cas de quelques matériaux verriers. Verres Refract. 1980;34(5):624-36.

Crichton SN, Tomozawa M, Hayden JS, Suratwala TI, Campbell JH. Subcritical crack growth in a phosphate laser glass. J Am Ceram Soc. 1999;82:3097-104.

Despetis F, Calas S, Etienne P, Phalippou J. Effect of oxidation treatment on the crack propagation rate of aerogels. J Non-Cryst Solids. 2001;285:251-5.

Despetis F, Etienne P, Etienne-Calas S. Subcritical crack growth in silica aerogel. J Non-Cryst Solids. 2004;344:22-5.

Duffours L, Woignier T, Phalippou J. Plasticity of aerogels under isostatic pressure. J Non-Cryst Solids. 1995;186:321-7.

Dumas J, Quinson JF, Serughetti J. Hierarchy of pores and mechanical behavior of wet silica gels. J Non-Cryst Solids. 1990;125:244-9.

Emmerling A, Fricke J. Scaling properties and structure of aerogels. J Sol-Gel Sci Technol. 1997;8:781-8.

Evans AG, Tappin G. Effects of microstructure on the stress propagate inherent flaws. Proc $\mathrm{Br}$ Ceram Soc. 1972;23:275-96.

Evans AG. Slow crack in brittle materials under dynamic loading conditions. Int $\mathrm{J}$ Fract. 1974;10:251-61.

Feng S, Sen P. Percolation on elastic networks: New exponent and threshold. Phys Rev Lett. 1984;52(3):216-9.

Gibson LJ, Ashby MF. Cellular solids structure and properties. Oxford, UK: Pergamon; 1988. 
Griffith AA. The phenomenon of rupture and flow in solids. Philos Trans R Soc London, Ser A. 1920;221:168-98.

Gross J, Fricke J. Ultrasonic velocity measurements in silica, carbon and organic aerogels. J Non-Cryst Solids. 1992;145:217-22.

Hafidi-Alaoui A, Woignier T, Pernot F, Phalippou J. Stress intensity factor in silica alcogels and aerogels. J Non-Cryst Solids. 2000;265:29-35.

Iler RK. The chemistry of silica. NewYork: Wiley; 1979.

Kantor Y, Webman I. Elastic properties of random percolating systems. Phys Rev Lett. 1984;52(21):1891-4.

Kistler SS. Coherent expanded aerogels. J Phys Chem. 1932;34:52-64.

Ma HS, Prevost JH, Jullien R, Scherer GW. Computer simulation of mechanical structure-property relationship of aerogels. J Non-Cryst Solids. 2001;285:216-21.

Michalske TA, Freiman SW. A molecular mechanism for stress corrosion in vitreous silica. J Am Ceram Soc. 1983;66(4):284-8.

Perrin L, Faivre AL, Calas S, Woignier T. Nano structural damage associated with isostatic compression of silica aerogels. J Non-Cryst Solids. 2004;333:68-72.

Phalippou J, Despetis F, Calas S, Faivre AL, Dieudonné P, Woignier T. Comparison between sintered and compressed aerogels. Opt Mater. 2004;26:167-74.

Pauthe M, Quinson JF, Hdach H, Woignier T, Phalippou J, Scherer GW. Autoclave treatment effect on silica alcogel texture. J Non-Cryst Solids. 1991;130:1-7.

Pirard R, Blacher S, Brouers F, Pirard JP. Interpretation of mercury porosimetry applied to aerogels. J Mater Res. 1995;10(8):2114-9.

Reynes J, Woignier T, Phalippou J. Permeability measurement in composite aerogels: application to nuclear waste storage. J Non-Cryst Solids. 2001;285:323-7.

Scherer GW, Pardenec SA, Swiateck RM. Viscoelasticity in silica. J Non-Cryst Solids. 1988;107:14-22.

Scherer GW, Smith DM, Qiu X, Anderson JM. Compression of aerogels. J Non-Cryst Solids. 1995;186:316-20.

Scherer GW. Crack tip stress in gels. J Non-Cryst Solids. 1992;144:210-4.

Stauffer D. Gelation in concentrated branched polymer solution. J Chem Soc Faraday Trans. 1976;2:1354-64.

Suratwala TI, Steele RA. Anomalous temperature dependence of sub-critical crack growth in silica glass. J Non-Cryst Solids. 2003;16:174-82.

Sullivan JD, Lauzon PH. Experimental probability estimators for Weibull plots. J Mater Sci Lett. 1986;5:1245-7.

Tokita M, Niki R, Hikichi K. Percolation theory and elastic modulus of gel. J Phys Soc Jpn. 1984;53(2):480-2.

West JK, Nicles R, Latorre G. Correlations between processing parameters. Ultrastructure and strength in gel-silica. In: Brinker CJ, Clark DE, Ulrich DR, editors. Materials research society symposia processing, vol. 121. Pittsburgh: Materials Research Society; 1988. p. 219-24.

Woignier T, Phalippou J. Mechanical strength of silica aerogels. J Non-Cryst Solids. 1988;100:404-8.

Woignier T, Phalippou J, Sempere R, Pelous J. Analysis of the elastic behavior of silica aerogels taken as a percolative system. J Phys Fr. 1988;49:289-93.

Woignier T, Phalippou J, Prassas M. Glasses from aerogels. J Mater Sci. 1990;25:3118-26.

Woignier T, Phalippou J, Hdach H, Larnac G, Pernot F, Scherer GW. Evolution of mechanical properties during the alcogel-aerogel-glass process. $\mathrm{J}$ Non-Cryst Solids. 1992;147-148:672-80.

Woignier T, Scherer GW, Alaoui A. Stress in aerogel during depressurization of autoclave: II silica gels. J Sol-Gel Sci Technol. 1994;3:141-50. 
Woignier T, Alaoui A, Primera J, Phalippou J, Scherer GW. Mechanical properties of aerogels: elastic or plastic materials? Key Eng Mater. 2009;391:27-44.

Woignier T, Alaoui A, Primera J, Scherer GW. Structural effect on the plastic behavior in highly porous glasses. Key Eng Mater. 2010;423:15-24.

Woignier T, Calas S, Reynes J. From nano composites aerogels to glass ceramics. Solid State Phenom. 2011;172-173:791-6.

Woignier T, Primera J, Alaoui A, Etienne P, Despestis F, Calas-Etienne S. Mechanical properties and brittle behavior of silica aerogels. Gels. 2015;1(2):256-75.

Zarzycki J. Critical stress intensity factors of wet gels. J Non-Cryst Solids. 1988;100:359-63. 